
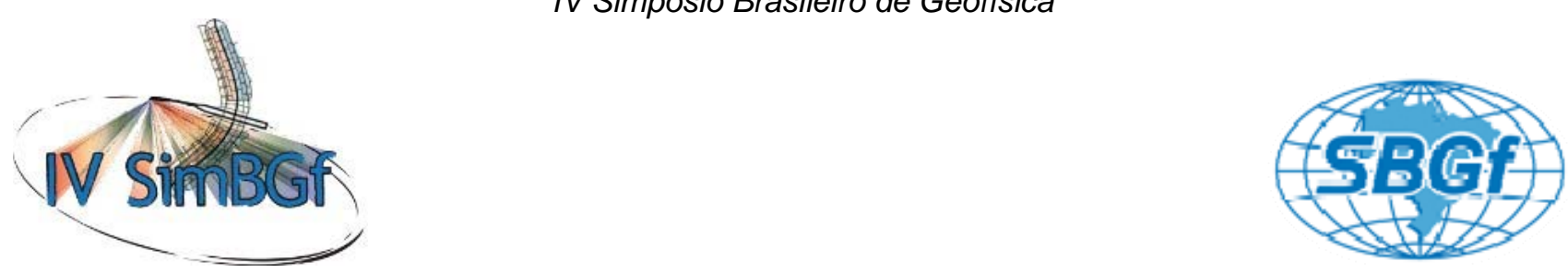

\title{
Estudos geoelétricos aplicados a caracterização geológica em uma área a sudoeste de Caçapava do Sul (RS)
}

Jobson de Oliveira*, UNIPAMPA, Brasil

Kleyzzer Rosso Rangel, UNIPAMPA, Brasil

Mario Jesus Tomas Rosales, Unipampa, Brasil

Copyright 2010, SBGf - Sociedade Brasileira de Geofísica

Este texto foi preparado para a apresentação no IV Simpósio Brasileiro de Geofísica, Brasília, 14 a 17 de novembro de 2010. Seu conteúdo foi revisado pelo Comitê Técnico do IV SimBGf, mas não necessariamente representa a opinião da SBGf ou de seus associados. É proibida a reprodução total ou parcial deste material para propósitos comerciais sem prévia autorização da SBGf.

\section{Abstract}

The study area is located approximately $3 \mathrm{~km}$ southwest of the city of Caçapava do Sul, geographically bounded by latitudes $-53.5201--53.5148$ and longitudes -30.5432 S - -30.53980 W.

Geologically falls on the westernmost edge of the granite suite Caçapava do Sul ( $\approx 540 \pm 11 \mathrm{Ma}$ ), composed of a geological context and syenogranites monzogranites.

The work aimed at the achievement of a geophysical resistivity in detailed scale covering a grid of points of measurements of $30 \times 5$ meters for electrical profiling technique and execution of three vertical electrical surface spatially distributed according to the NW - SE with the objective of contributing to the geological characterization of the subsurface of the study area

\section{Introdução}

A região de Caçapava do Sul, onde se insere a área de estudo, localiza-se na unidade geotectônica denominada Escudo Sul-rio-grandense situada na porção meridional da Província Mantiqueira (Almeida et al., 1977). Esta área registra os eventos relacionados ao Ciclo Brasiliano/PanAfricano (Porada, 1979) no sudeste da América do Sul.

A área de estudo se localiza na zona rural aproximadamente $3 \mathrm{~km}$ a sudoeste da cidade de Caçapava do Sul no estado do Rio Grande do Sul (RS), ocupando em superfície $0,62 \mathrm{~km}^{2}$ e delimitada geograficamente pelas latitudes $-53.5201--53.5148 \mathrm{~S}$ e longitudes -30.5432 - -30.5398 W (Figura 1).

Geologicamente se localiza no Complexo Granítico Caçapava do Sul (CGCS) composto principalmente por granodioritos, monzogranitos e sienogranitos (Nardi \& Bitencourt, 1989) e possui idade magmática em torno de $550 \mathrm{Ma}$ (Sartori \& Kawashita, 1985; Leite et al., 1995). As estruturas de deformação planar e lineares dessa unidade revelam atuação de zonas de cisalhamento transcorrentes durante a geração destas rochas.

O trabalho visou à realização de um levantamento geofísico de eletrorresistividade em escala de detalhe cobrindo uma malha de pontos de medições de $30 \times 5$ metros para a técnica de Caminhamento elétrico e a execução de três Sondagens elétricas verticais distribuídas espacialmente em superfície segundo a direção NW - SE, com o objetivo de contribuir para a caracterização geológica em sub-superfície da área de estudo, em termos de mapear as ocorrências de fraturas no granito e inferir a sua continuidade em profundidade, delinear espacialmente em profundidade o contato do topo do granito (rocha sã) e inferir a profundidade do nível freático na área de estudo e a provável direção do fluxo das águas subterrâneas.

Os dados de eletrorresistividade de Caminhamento Elétrico e de Sondagem Elétrica Vertical foram interpretados qualitativamente seguindo uma metodologia convencional e quantitativamente mediante técnicas de inversão.

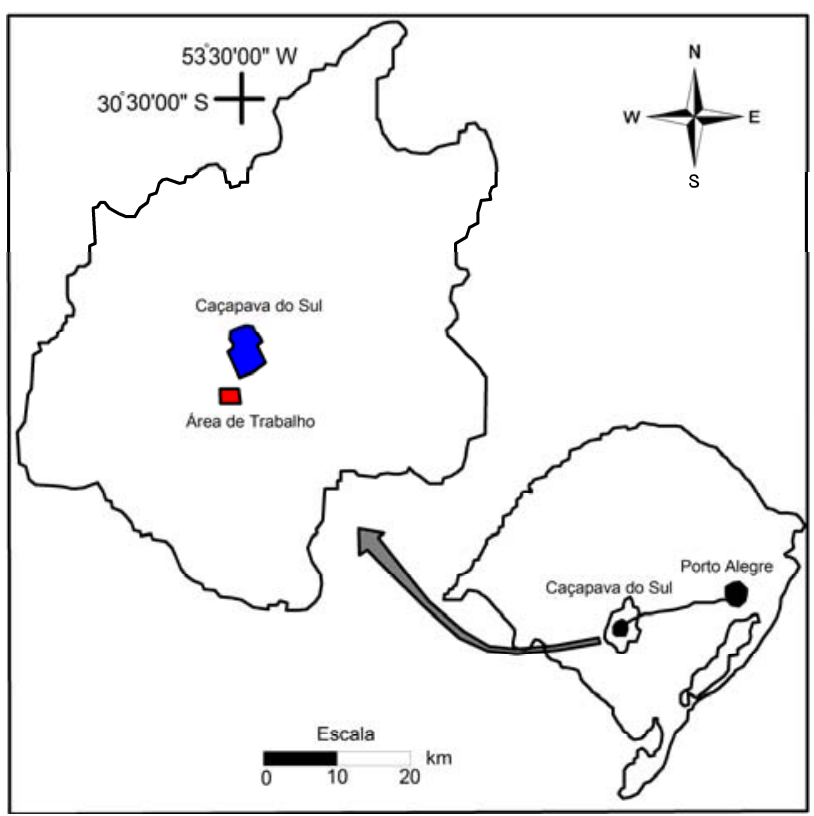

Figura 1 - Esquema ilustrativo de localização da área de estudo a sudoeste de Caçapava do Sul. (Fonte:

modificado do IBGE, 2007)

Arcabouço geológico da área de estudo. 
Conforme pode observar-se no mapa geológico da Figura 2, a área de estudo encontra-se em um contexto geológico regional limitado a oeste por uma faixa com disposição espacial norte-sul da Sequência metamórfica Vacacaí ( $\approx 550 \mathrm{Ma}$ ), constituída por metapelitos, xistos quartzo-feldspáticos, quartzitos e rochas metavulcânicas, apresentando nos primeiros horizontes do solo uma cobertura formada por um manto de alteração de cor avermelhada com presença de material orgânico.

As altitudes topográficas caracterizam um relevo suavemente ondulado com variações de 430 a 418 metros na direção norte. O marco tectônico mostra a área inserida num contexto regional caracterizado pela presença de falhas com transcorrência sinistral seguindo um trend na direção NW-SE, alguns afloramentos de granito na área, mostram evidencias de um alto grau de alteração e a presença de rochas fraturadas.

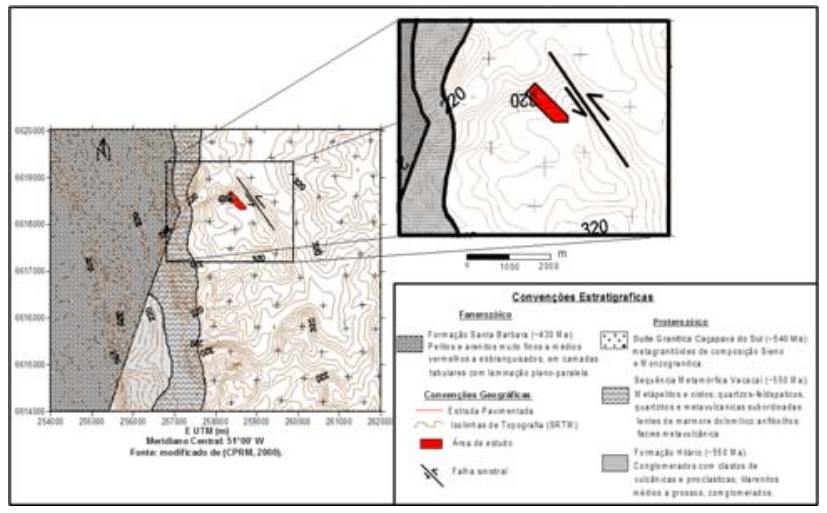

Figura 2 - Mapa geológico regional mostrando a área de estudo (adaptado de CPRM, 2000) e dados topográficos do SRTM (Shuttle Radar Topography Mission, USGS/NASA, 2007).

\section{Levantamento de eletroresistividade.}

Para efetuar as medições referentes à aquisição de dados de eletrorresistividade, foi utilizado um Eletrorresistivímetro analógico de fabricação nacional de marca TECTROL.

Este equipamento se divide em dois módulos: o modulo transmissor que envia corrente continua até $500 \mathrm{~mA}$, e o modulo denominado receptor que mede a diferencia de potencial entre os eletrodos de medição em miliVolts $(\mathrm{mV})$.

\section{Caminhamento Elétrico (CE)}

As medidas de CE foram realizadas utilizando o arranjo dipolo-dipolo com espaçamento entre os eletrodos de 5 e 10 metros. $O$ espaçamento de 5 metros foi utilizado em 4 linhas de medições com 120 metros de comprimento, conforme uma malha regular com uma separação entre linhas de 30 metros, e distância entre pontos 5 metros (dipolo $=5$ metros), segundo a direção (NE-SW), com a finalidade de obter um conhecimento detalhado da área segundo a extensão lateral e em diferentes profundidades, através de mapas de resistividade aparente a diferentes níveis teóricos. Com o objetivo de estender o reconhecimento geoelétrico aos setores de prováveis contatos entre o granito aflorante e o manto de alteração do solo, existentes nas bordas oeste e leste da área de estudo. Foi realizada uma linha de medição de Caminhamento Elétrico (A-A') com um espaçamento entre os eletrodos de 10 metros (dipolo $=10$ metros).

O mapa da Figura 3 mostra a malha de aquisição de dados de CE e o posicionamento das SEVs na área de estudo, assim como a presença de algumas feições fisiográficas presentes na superfície do relevo topográfico.

\section{Sondagem Elétrica Vertical (SEV)}

No caso particular da técnica de SEV com o arranjo Schlumberger (Orellana, 1982), foi utilizada uma disposição de maneira que os eletrodos ( $A B, M N)$ permanecessem simetricamente com relação ao centro do arranjo, tornando este ponto como referencia para a leitura dos dados. Foram realizadas três Sondagens elétricas verticais distribuídas espacialmente em superfície segundo a direção NW - SE, com uma abertura máxima entre os eletrodos de corrente $(\mathrm{AB} / 2)$ de 100 metros.

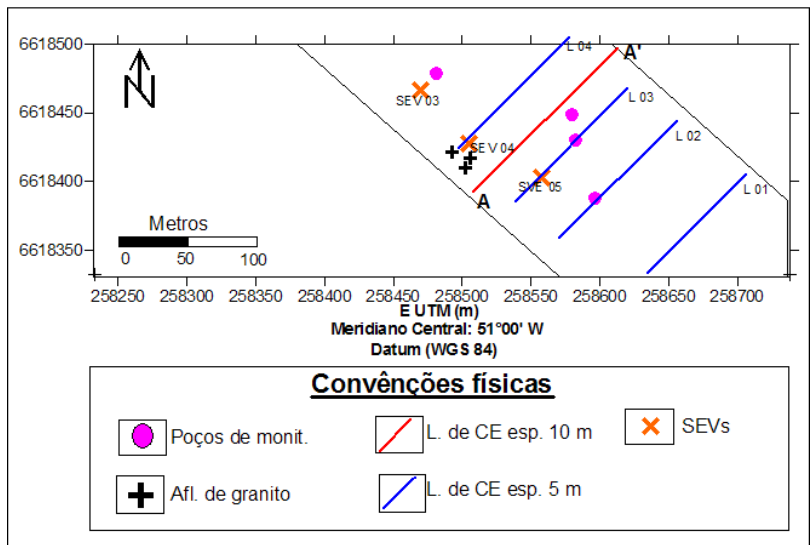

Figura 3 - Mapa esquemático mostrando a malha de aquisição de dados de CE, o posicionamento das SEVs e a localização de poços de monitoramento.

\section{Interpretação dos dados de Caminhamento Elétrico}

O mapa de resistividade aparente apresentado mostra os resultados obtidos ao longo das linhas de CE na área de estudo, para o nível de profundidade teórica de 15 metros (Figura 4). A interpretação do mapa assume um caráter qualitativo ao tentar inferir setores anômalos de altos e baixos de resistividade elétrica e correlacionar eles com uma provável continuidade em profundidade, associados aos diferentes litotipos presentes na área.

Observa-se na porção norte da área a presença de valores de resistividade intermediários em torno de 200 Ohm.m, associado a presença de um solo seco com material síltico argiloso.

Destaca-se na porção central a presença de um eixo com valores baixos de resistividade (100 - 150 Ohm.m) 
associado provavelmente a presença de fraturas no granito que poderiam eventualmente estar preenchidas com um material mais condutivo que poderia tratar-se de argila ou eventualmente a presença de percolação de água.

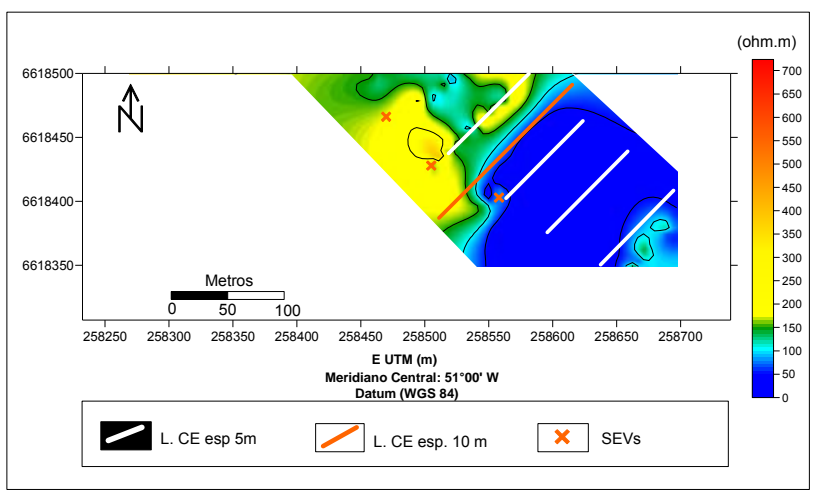

Figura 4 - Mapa de resistividade aparente a 15 metros de profundidade. Intervalo de contorno: 50 Ohm.m.

É possível ressaltar a partir dos resultados da interpretação do mapa de contorno de resistividade aparente a uma profundidade de 15 metros (Figuras 4), a presença de uma zona de fratura que apresenta continuidade em profundidade e se alonga na direção NW-SE da área, essa zona de fratura seria um canal propicio para a circulação de águas subterrâneas na área, o que poderia correlacionar-se com a presença de um eixo com valores baixos de resistividade.

\section{Modelo de resistividade obtido por inversão}

Como resultados gráficos das medições obtidas com a técnica de caminhamento elétrico foram gerados pseudoseções de resistividade aparente bidimensional (onde a resistividade varia em profundidade e lateralmente). No caso particular das pseudo-seções de resistividade aparente foram calculados modelos 2D mediante 0 programa de inversão RES2DINV Ver. 3.57 (2008).

A Figura 5 mostra o modelo de resistividade obtido com inversão da Linha A-A' de CE com dipolo $10 \mathrm{~m}$.

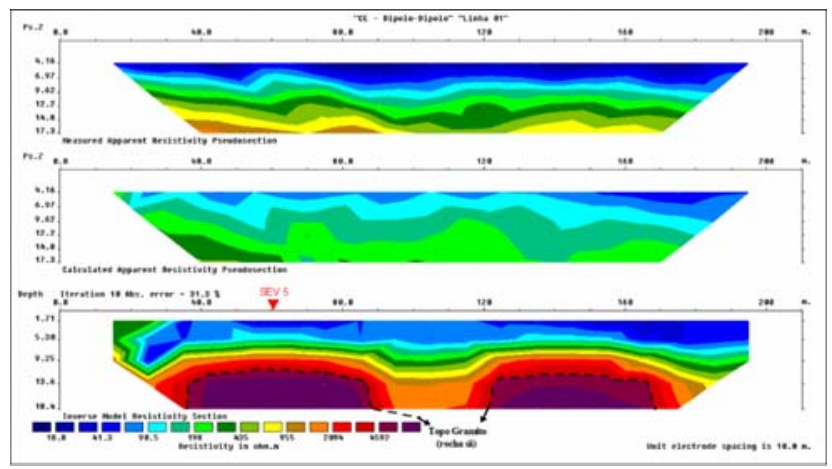

Figura 5 - Modelo de resistividade da Linha $A-A^{\prime}$, mostrando a posição da SEV 5.

O modelo de resistividade elétrica mostra resistividades altas, na faixa de 4000 Ohm.m, a partir de $12 \mathrm{~m}$ de profundidade, indicando o possível contato do topo do granito sem alteração (rocha sã).

Na porção central do modelo nota-se uma feição de baixa resistividade de aproximadamente 500 - 600 Ohm.m, mostrando um leve incremento em profundidade, associada provavelmente a presença de rocha alterada apresentando fraturas preenchidas com material argiloso.

A Figura 6 mostra um modelo geológico geofísico inferido a partir da interpretação do modelo de resistividade da Linha A - A'.

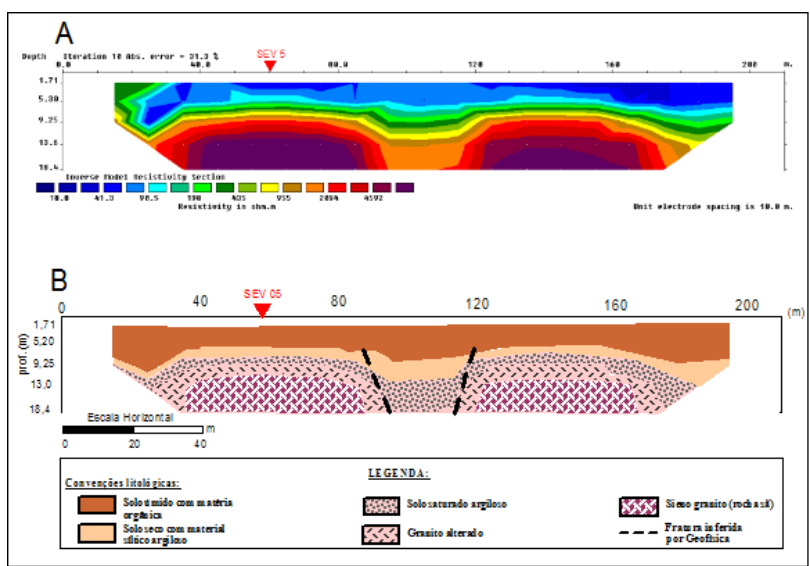

Figura 6 - Modelo de resistividade da linha $A$ - A' de CE:

\section{A - Modelo de resistividade obtido por inversão \\ $B$ - Modelo geológico inferido a partir do modelo de resistividade.}

O modelo geológico apresenta uma camada superficial com resistividades baixas composta por solo úmido e material orgânico, na seqüência observa-se uma camada com valores mais altos de resistividade composta por solo seco com material síltico argiloso, aproximadamente aos 10 metros de profundidade encontra-se uma camada fina de solo saturado argiloso cobrindo uma camada de granito alterado, posicionada sobre 0 topo do embasamento granítico (rocha sã) posicionado aproximadamente a uma profundidade de 15 metros.

\section{Interpretação das curvas de SEVs.}

Para calcular a distribuição de resistividade elétrica no subsolo se utilizam programas de inversão dos dados de resistividade elétrica, no caso particular da SEV, as curvas de resistividade obtidas em campo, em função da distância $A B / 2$, se ajustam mediante um algoritmo matemático visando encontrar um modelo de camadas de resistividade elétrica em função da profundidade (1D), cuja resposta de resistividade aparente seja compatível com os dados observados no campo.

Foi utilizado para a inversão dos dados das SEVs o programa IPI2Win Version 3.0.1a. elaborado pela Universidade de Moscou, 2003.

As Figuras 7, 8 e 9, mostram os modelos gerados através do processo de inversão das SEVs realizadas na área de estudo (SEV 3, SEV 4 e SEV 5). 
As curvas de SEVs com dados observados no campo foram classificadas de acordo com a seqüencia das camadas elétricas compatíveis com cortes geológicos que afloram nas proximidades da área de estudo.

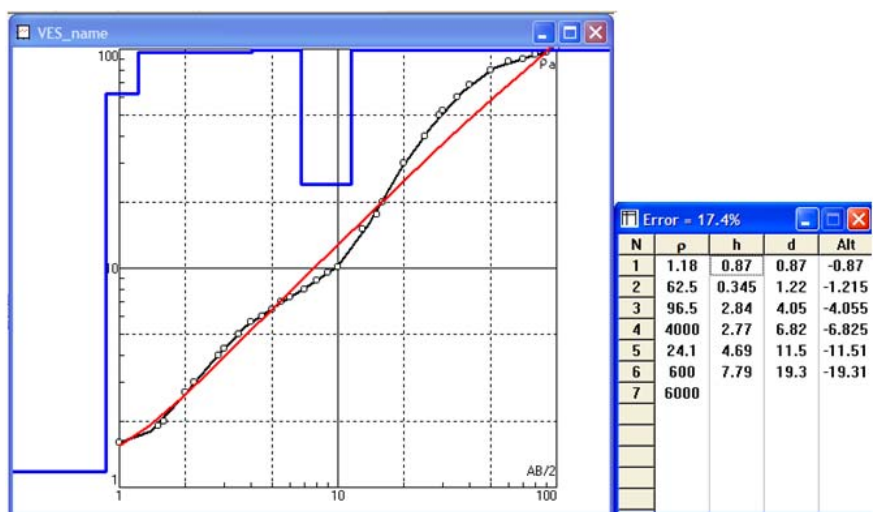

Figura 7 - Modelo de Inversão para a SEV 3 (IPI2Win, 2003).

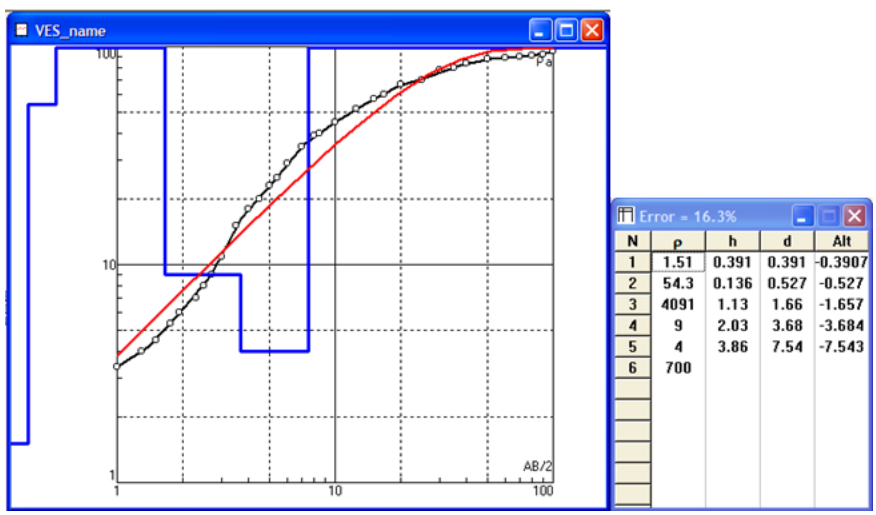

Figura 8 - Modelo de Inversão para a SEV 4 (IPI2Win, 2003).

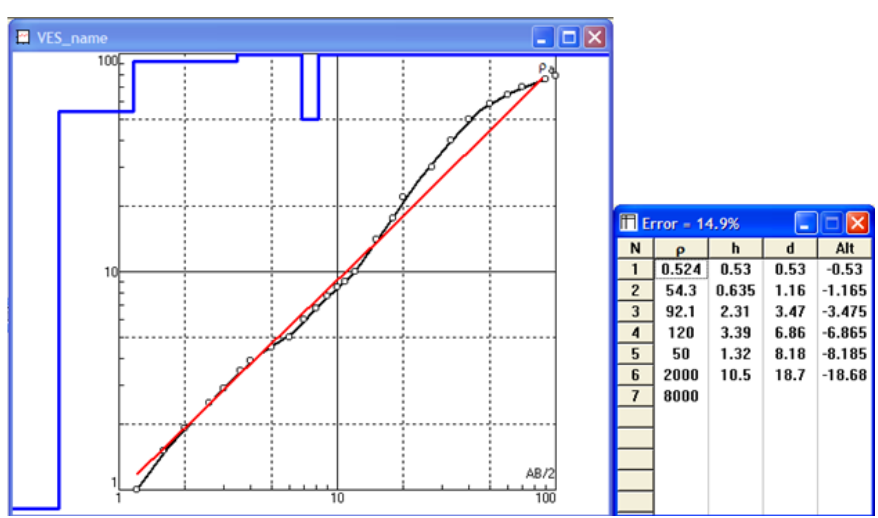

Figura 9 - Modelo de Inversão para a SEV 5 (IPI2Win, 2003).

Para as curvas de SEVs os modelos básicos iniciais obtidos conforme o processo de inversão baseia-se de maneira geral em curvas de seis camadas do tipo AKHA.

\section{Descrição da seção geológica - geofísica baseada na interpretação dos modelos obtidos para as SEVs.}

Nas Figuras 10 e 11, podem-se observar os resultados obtidos ao longo da seção geológica - geofísica baseada na interpretação dos modelos obtidos para as SEVs, a presença de pacotes de espessuras diferentes caracterizados por diferentes litologias e diferentes patamares de valores de resistividade.

A interpretação ao longo da seção que correlaciona às três Sondagens elétricas verticais (SEV 3, SEV 4 e SEV $5)$ na direção NW-SE, se caracteriza por valores de cotas topográficas em torno de 430 metros.

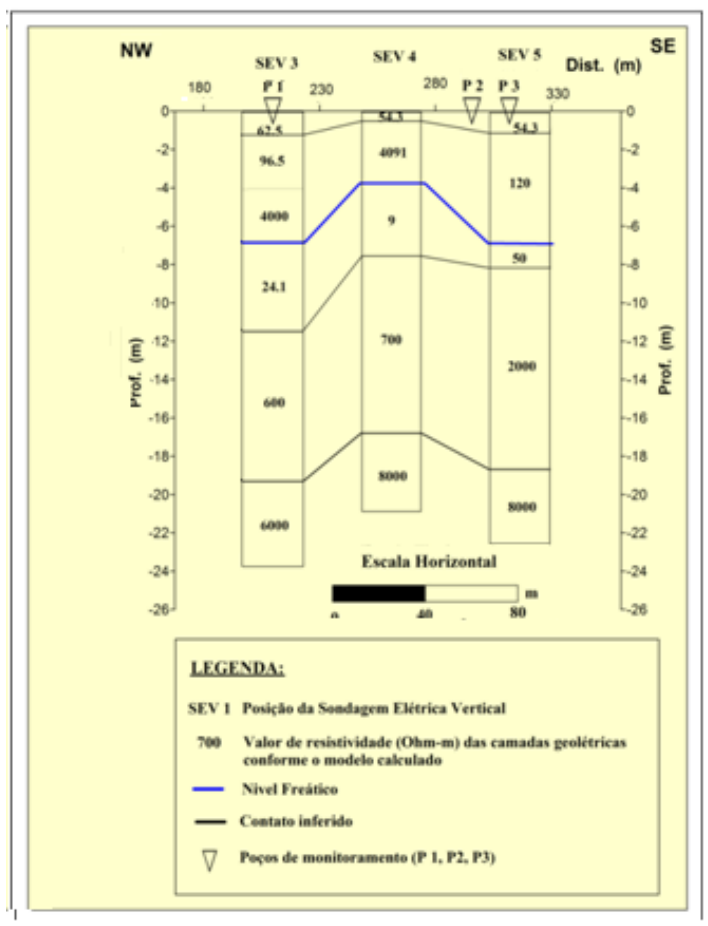

Figura 10 - Seção geofísica baseada na interpretação dos modelos obtidos para as SEVs.

$\mathrm{Na}$ porção central observa-se a presença de um pacote superior com uma espessura aproximada de 1,2 metros e valores baixos de resistividade (6 - 120 Ohm.m) associado a um manto de alteração composto por um solo úmido com material orgânico.

Entre a SEV 3 e SEV 4 é possível correlacionar a presença de um corpo de granito com formato de uma fina cunha de uma espessura aproximada de 3 metros, apresentando o topo superior mais próximo da superfície no ponto posicionado da SEV 4.

O nível freático entre a SEV 3 e SEV 4 foi inferido a uma profundidade de aproximadamente 6,8 metros e 4 metros seguindo a direção sudeste da área de estudo.

Aproximadamente a partir dos 10 metros de profundidade infere-se a presença de um granito fraturado com alto grau de umidade apresentando valores de resistividade em torno de 600 a 700 Ohm.m.

Infere-se a presença do contato do topo do granito, sem alterações, denominado de rocha sã, a uma profundidade aproximada de 19 metros, apresentando valores em torno de 6000 Ohm.m.

$\mathrm{Na}$ porção Sul, observa-se a presença de um pacote superior com uma espessura aproximada de 1,2 metros e valores baixos de resistividade (54,3 Ohm.m) associado a 
um manto de alteração composto por um solo úmido com material orgânico que é possível correlacionar com o setor central.

O nível freático foi inferido a uma profundidade de aproximadamente 6,9 metros o qual é possível correlacionar com a localização da SEV 5.

Infere-se a presença do contato do topo do granito (rocha sã) a uma profundidade aproximada de 19 metros, apresentando valores em torno de 8000 Ohm m o qual é possível correlacionar com a porção central da área de estudo.

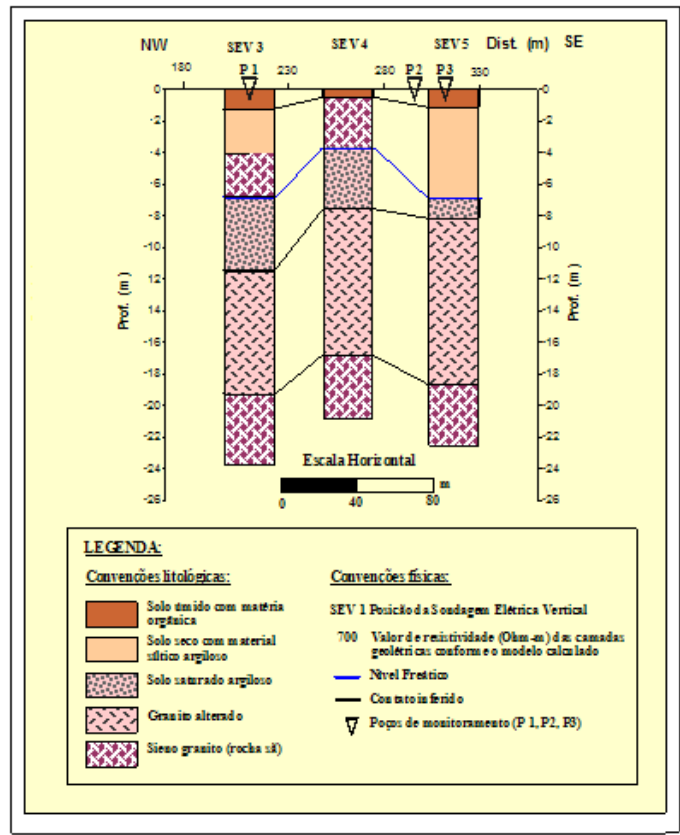

Figura 11 - Seção geológica - geofísica baseada na interpretação dos modelos obtidos para as SEVs.

Consistência na interpretação dos modelos da SEV 3 e SEV 5 com parâmetros conhecidos em poços de monitoramento na área de estudo.

No modelo obtido para a SEV 3 , foi correlacionada a profundidade inferida para a presença do nível freático de aproximadamente 6,82 metros, com relação ao nível estático da água no Poço 1, de 6,5 metros (Figura 11).

No modelo obtido para a SEV 5, foi correlacionada a profundidade inferida para a presença do nível freático de aproximadamente 6,86 metros, com relação ao nível estático da água no Poço 2, de 6,1 metros e no Poço 3 de 7,2 metros (Figura 11).

A Figura 12 apresenta uma tabela com os dados georreferenciados dos poços localizados na área de estudo.

\begin{tabular}{|c|c|c|c|c|c|}
\hline Poses & $\begin{array}{l}\text { Loedizacto (UTM) } \\
\text { Zona } 22 \mathrm{~J}\end{array}$ & Ntritude do local (m) & Profundidade (m) & Nivel estático (m) & Data \\
\hline Poso 1 & $\begin{array}{r}\text { W } 258582 \\
6618430\end{array}$ & 429 & 8.50 & 6.50 & $05: 1009$ \\
\hline Poso 2 & $\begin{array}{r}\text { W } 258578 \\
6618448\end{array}$ & 428 & 7,40 & 6,10 & 05/1009 \\
\hline Poso 3 & $\begin{array}{r}\text { W } 258481 \\
6618477\end{array}$ & 429 & 9,20 & 7,20 & $05: 1009$ \\
\hline Pose 4 & $\begin{array}{r}\text { W 258596 } \\
6618388\end{array}$ & 430 & 9,00 & 7,00 & 05:10,09 \\
\hline
\end{tabular}

Figura 12 - Tabela com os dados dos poços localizados na área de estudo.

A Figura 13 mostra o Modelo geológico geofísico integrando dados geoelétricos das técnicas de CE e SEV na área de estudo a partir do modelo obtido por inversão para a SEV 5 junto ao modelo de resistividade obtido por inversão para a Linha A-A' de CE.

É notório destacar a consistência estabelecida na interpretação geofísica - geológica dos dois modelos de maneira conjunta.

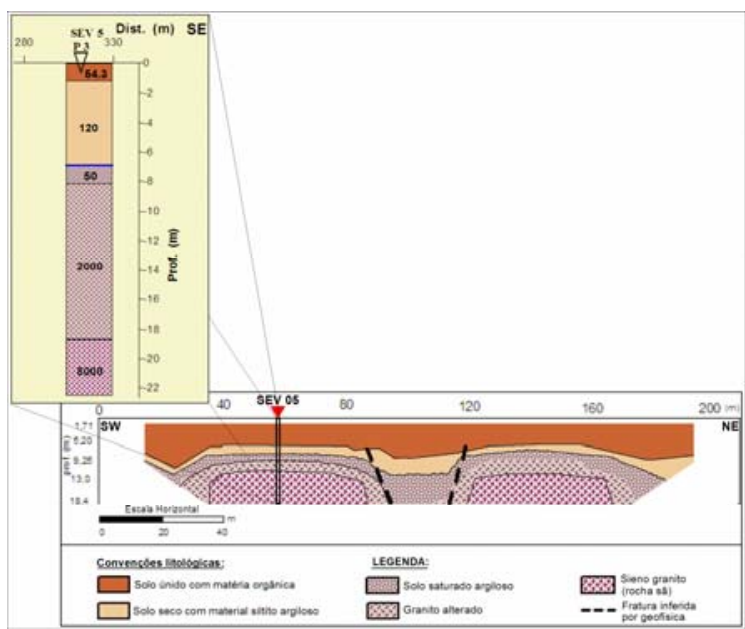

Figura 13 - Modelo geológico geofísico integrando dados geoelétricos das técnicas de CE e SEV na área de estudo.

\section{Conclusões}

Os resultados obtidos no trabalho se mostram consistentes do ponto de vista de interpretação geológico - geofísica de maneira integrada dos dados geofísicos oriundos dos levantamentos de eletrorresistividade.

Aportou parâmetros geométricos referentes à extensão lateral e em profundidade dos primeiros horizontes do solo, em termos de estabelecer e delinear possíveis contatos entre o granito sem alteração (rocha sã) e a rocha alterada (solo intemperizado).

Caracterização geofísica e identificação espacial em profundidade da presença de fraturas no granito e seu inferimento de continuidade até níveis superiores próximos da superfície.

Delineamento espacialmente em profundidade do contato do topo do granito (rocha sã).

Inferimento da profundidade do nível freático na área de estudo e a provável direção do fluxo das águas subterrâneas.

Confeccionou um modelo geofísico geológico baseado na interpretação dos dados geoelétricos de Sondagem elétrica vertical (SEV) para a área de estudo.

Os resultados obtidos no trabalho foram satisfatórios e constituem resultados pioneiros para a área de estudo em termos de uma abordagem em escala de detalhe de reconhecimento geofísico geológico. 
Recomenda-se para futuros trabalhos geofísicos de esta natureza na região de estudo a continuidade de execução de levantamentos geofísicos em escala de detalhe visando a utilização de novas técnicas de exploração geofísica e a posterior integração e interpretação desses dados.

\section{Agradecimentos}

Nossos agradecimentos a UNIPAMPA pela acessibilidade a realização desta pesquisa e a disponibilidade dos equipamentos e instrumentação de campo. Ao grupo de alunos que nos ajudaram na execução dos levantamentos de campo.

Agradecemos de maneira pessoal ao Prof. Dr. Mario Jesus Tomas Rosales pela orientação do trabalho.

\section{Referências}

ALMEIDA, F. F. M.; Hasui, Y.; Brito Neves, B. B. \& FUCK, R. A. Províncias Estruturais Brasileiras. In: SIMPÓSIO DE GEOLOGIA DO NORDESTE, 8., Campina Grande, Atas..., SBG, p. 363-391, 1977.

BOBACHEV A; I MODIN; V. SHEVNIN. 2003 IPI2Win software. Versión 3.0.1a. Geoscan-M Ltd. Moscow State University. Russia.

CPRM - SERVIÇO GEOLÓGICO DO BRASIL. (2000). Programa Levantamentos Básicos do Brasil - Carta Geológica Folha Cachoeira do Sul SH22-Y-A.

IBGE - (2007) - Mapas Interativos - www.ibge.gov.br/

Nardi, L. V. S. \& Bitencourt, M. F. A. S. 1989. Geologia, petrologia e geoquímica do Complexo Granítico de Caçapava do Sul, RS. Revista Brasileira de Geociências, 19: 153-169.

ORELLANA, E. 1982. Prospección geolétrica en corriente continua. Paraninfo, Madrid, 1-578.

PORADA, H. 1979. The Damara-Ribeira Orogen of the Pan African-Brasiliano Cycle in Namibia (Southwest Africa) and Brazil as interpreted in terms of continental collision. Tectonophysics, 57: 237-265, 1979.

RES2DINV Ver. 3.57. Geotomo Software Sdn Bhd, Malaysia, 2008.

SARTORI, P. L. P. \& KAWASHITA, K. Petrologia e geocronologia do Batólito granítico de Caçapava do Sul, RS. In: SIMPÓSIO SULBRASILEIRO DE GEOLOGIA, 2., Florianópolis, 1985, Atas...,SBG, p. 102-115, 1985.

TECTROL - Equipamentos elétrico eletrônicos LTDA. 